\title{
CONDITIONS FOR ESTABLISHING ADMINISTRATIVE-TERRITORIAL UNITS - MUNICIPALITIES IN THE REPUBLIC OF BULGARIA
}

\author{
D. Ushatova* \\ Department of Regional Development, Faculty of Economics, Trakia University, \\ Stara Zagora, Bulgaria
}

\begin{abstract}
The study aims to show the deficits in the legislation regarding the conditions for establishing municipalities as administrative-territorial units. An experimental methodology for assessing current regulatory conditions for establishing a new municipality in Bulgaria has been proposed, and the results from applying it have been presented. Conclusions were made per group of municipalities. A comparison was drawn between the constitutionally established role of municipalities as the main Administrative Territorial Units, in which local self-government is exercised, and the conditions for establishing a municipality, defined by the Law on the Administrative-Territorial Structure of the Republic of Bulgaria. Based on the results of the study, we have proposed to improve the understanding of the need for real forms in the social and economic sphere, instead of populist promises for a new administrative-territorial division of the country and the future positive effects determined by it.
\end{abstract}

Key words: a methodology for evaluation, local self-government, reforms in the social and economic sphere

\section{INTRODUCTION}

Since 1989, in the period of developing democratic local self-government, the Bulgarian local authorities have dealt with several crisis situations, which have had a negative financial effect on local budgets. Hyperinflation in 1997 and the global financial and economic crisis of 2007-2008 have generally led to an increase in the indebtedness of municipalities and the deterioration of the scope and quality of local public services. The cause of the foreseen crisis in 2020 and the coming years is the Covid-19 pandemic, which has affected the whole world. The panic caused by the epidemic is expected to become an unlocking factor for the new global financial and economic crisis predicted by a number of economists for at least two years. Unlike the shock to the global economy in the previous global crisis, the causes for the current one have been provoked by the measures against

\footnotetext{
*Correspondence to: Daniela Ushatova, PhD student, Department of Regional Development, Faculty of Economics, Trakia University, Stara Zagora, Bulgaria, e-mail: daniushatova@gmail.com
}

the Covid-19 epidemic, which were announced in most countries - bans and restrictions, closure of almost entire sectors, postponement of major events, new costs of anti-epidemic protection and support for the most affected, etc. In the difficult conditions of recovery of the economy after such crises, the issue of the optimal approach to public spending cuts has traditionally appeared on the agenda. As part of such cuts, calls for the reduction of the number of administrative-territorial units and administrative cuts have often been heard. The purpose of this report is to prove that there is no link between establishing municipalities for their own sake and their effectiveness and usefulness to people. From the point of view of public expenditure on local self-government, fair approaches should be sought to assess how their bodies operate and work (as a degree of functional commitment to government, regional development, and territorial structure, and as an opportunity for them to carry out their delegated management functions effectively).

The administrative division of a country is related to the separation of administrative- 
territorial units (ATU). ATU is a structural part of the territory of the state with legal status and boundaries, serving as a spatial basis for the establishment of the system of bodies of state government or local self-government and for determining the territorial limits of their competences, regulated by law (1).

By definition, the purpose of the administrative-territorial structure is to create a system to meet the interests and needs of the population at the local level. It is for these reasons that in the old Member States such as France, for example, which leads the ranking in the number of municipalities in the EU, municipalities have not merged, but options are sought to create more opportunities for inter-municipal cooperation.

For any public structure, business and citizens in a crisis and post-crisis period, it is important to properly assess the situation concerned, the effectiveness of the measures implemented, learn the lessons learned from the crisis and take action to minimise such risks in the future. The right decisions and strategies also depend to a large extent on the capacity of local authorities and state institutions. Here, the role of local leaders is crucial, given that the municipalities are the closest level of government to citizens and have a level of responsibility and their own revenue sources defined by the Constitution of the Republic of Bulgaria, the Local Self-Government and Local Administration Act and the Local Taxes and Fees Act.

The infection crisis has shown that it does not matter how big a municipality or a community is, but rather what protocols, rules and conditions are followed to reduce risks to people. The fact that a sustainable administrative-territorial structure has been built in the country helped largely within a few months to set up an organization to contain the infection. In the course of the implementation of the anti-epidemic measures, there was no municipality that had failed or denied public services to its citizens, even on the contrary municipalities managed to cope, even better in "communicating" with the local population and business. Examples include the many solutions to further support businesses and citizens concerned, such as reducing, cutting or remission of rents and fees. A significant, unplanned financial resource was mobilised in the annual budgets to meet the new obligations for disinfection and reorganisation of the activity. This support is part of the public resource, part of the state and municipal budgets. In general, higher public spending is compensated either by cuts to other such expenditure, or by an increase in taxes and fees, or of debt. Since in the event of crises in our country it is more common to resort to cuts in budget expenditure, the topic of introducing an administrative reform is expected to appear again on the agenda, or in other words to reduce the number of administrative structures. In such situations, ideas for the consolidation of municipalities are often heard. In this case, it is crucial to clarify the role of municipalities in a normal and crisis situation, as well as their compliance with the law. The subsequent recovery, or rather reform towards the new reality, will largely depend not only on the administrative-territorial division of the country, but on the flexibility to make decisions, on the availability of liquid resources at the local level and on the timely minimization of future risks.

In this regard, the purpose of this study is to prove that the complexity of fulfilling the conditions for the establishment of a municipality can also be applied to similar ideas, and the financial effects on both the people in the municipalities and the municipal budgets should be taken into account.

\section{Exposition}

\subsection{Main features of Bulgarian municipalities and European comparisons.}

In Bulgaria, as of 2015, there are 265 municipalities. Compared to 1990 or during these 30 years of transition, the number of municipalities has increased by $6.4 \%$, mainly by separating settlements from another municipality.

Despite the desire of some researchers and politicians to launch a reform for the consolidation of municipalities, Bulgarian municipalities are neither so numerous, nor serve such scarce populations or territory, unlike a number of European countries. In the next Table 1, we have presented the surveyed indicators for Bulgaria for ATU municipalities, compared to the average for European member countries according to Eurostat data for 2018. 
Table 1. Main indicators for ATU - municipalities in Bulgaria, compared to EU 27

\begin{tabular}{|l|l|l|l|l|}
\hline Indicators & $\begin{array}{l}\text { Average for } \\
\text { countries with } \\
\text { higher than EU } \\
\text { average levels }\end{array}$ & EU average 27 & $\begin{array}{l}\text { Bulgaria's rank } \\
\text { (from highest to } \\
\text { lowest value) }\end{array}$ & $\begin{array}{l}\text { Value of the } \\
\text { indicator for }\end{array}$ \\
\hline $\begin{array}{l}\text { By number of } \\
\text { municipalities }\end{array}$ & 12814 & 3530 & 19 & 265 \\
\hline $\begin{array}{l}\text { By average population } \\
\text { per municipality }\end{array}$ & 43572 & 15125 & 22 & 26415 \\
\hline $\begin{array}{l}\text { By average area in } \\
\text { sq.km. per municipality }\end{array}$ & 810 & 259 & 8 & 418 \\
\hline $\begin{array}{l}\text { By degree of deviation } \\
\text { max/min. population per } \\
\text { municipality }\end{array}$ & 511545 & 286781 & 15 & 1752 \\
\hline $\begin{array}{l}\text { Source: Eurostat } \\
\text { Bunaly }\end{array}$ & & & & \\
\hline
\end{tabular}

Source: Eurostat

Table 1 shows that the indicators of the number of municipalities, the population living in them and their territory in Bulgaria are far below the EU average. In other words, 13 times fewer Bulgarian municipalities serve on average a $75 \%$ larger population and $61 \%$ more territory than the EU average.

According to the information presented in the published Draft of Updated National Concept for Spatial Development for the period 20132025 (2) the main data for the country are:

Area: 110371,9 sq.km.

Population: 7000039 (as of 31.12.2018), $5159129(73,7 \%)$ in urban areas

Age structure: 0-14 years - 14.4\%, 15-64 years $-64,3 \%, 65+-21,3 \%$

Share of the population with higher education $-19.6 \%$

Population density: 63.4 people/sq.km

Administrative division: 6 regions level 2 (NUTS2), 28 districts, 265 municipalities, 5256 settlements (as of 31.12.2018), 257 towns, 4999 villages

Communication-transport network - road network density: $0.18 \mathrm{~km} / \mathrm{km} 2$

Thermal Springs: 148 deposits

World Natural and Cultural Heritage: Protected areas $-5.3 \%$ of the territory of the country; Natura 2000 protected areas $-34.6 \%$ of the territory of the country; 2 World Heritage Sites; 7 sites of tangible world cultural heritage.

The said document also states that the spatial location of the population is uneven at all territorial levels:

- $\quad$ NUTS 1 - Great contrast between the two statistical units (NUTS 1). The contrast between the geographical Southern and Northern Bulgaria is even greater;

- NUTS 2 - SWR (30.0\%) and SCR $(20.1 \%)$ - inhabited by half of the population; NWR with a share of $10.6 \%$ (742 thousand people), twice less the size of the SCR and three times smaller than the SWR, is already below the population criterion of a level 2 area;

- $\quad$ NUTS 3 - the smallest region of Vidin (84 865 people, $1.2 \%$ of the population of the country) can be applied 15.6 times in the largest area - Sofia-city - 1328120 people, $19.0 \%$;

- LAU 2 - the unevenness of the population by municipalities is even more expressed. The smallest municipality of Treklyano (758 people) can fit 1752 times on the territory of Sofia Municipality. In the nine municipalities with over 100,000 inhabitants live $41.3 \%$ of the country's population. In 73 municipalities with under 6,000 people live only $4.0 \%$ of the country's population.

When comparing the positions of the values of the indicators for Bulgaria, the negative trend for the unjustified focus of the problems of the administrative-territorial structure on the municipalities, and only on the population, is 
clearly distinguished against the EU average. In this sense, it can be said that the claims that the Bulgarian municipalities are "too numerous and their further consolidation should be reconsidered and approached" are insufficiently substantiated.

1.2. Regulatory requirements regarding the establishment of ATU, respectively for their closure.

The Law on the Administrative-Territorial Structure of the Republic of Bulgaria (LATSRB) (3) governs the establishment of administrative-territorial and territorial units in the Republic of Bulgaria, as well as the implementation of administrative-territorial changes. In the country, the main administrative-territorial units (ATU) are the districts and municipalities, and the constituent administrative-territorial units in the municipalities are the mayoralties and regions. The law also stipulates that settlements and settlement entities are territorial units.

Each district, municipality and mayoralty have territory, borders, population, name and administrative centre, whereas the region has territory, borders, population and name.

The terms and conditions for the establishment of a municipality have been set in art. 8 and 9 of LATSRB. The conditions for the establishment of a municipality include:

- $\quad$ population of over 6000 people in total in the settlements to be included in the municipality;

- $\quad$ presence of a settlement - a traditional unifying centre with established social and technical infrastructure, providing services for the population;

- inclusion of all neighbouring settlements for which there are no conditions for establishing a separate municipality or which cannot join another neighbouring municipality;

- maximum road transport distance of the settlements from the centre of the municipality not more than $40 \mathrm{~km}$;

- $\quad$ possibility to finance the expenditures of the newly created municipality with revenues within the meaning of art. 45, para. 1, item 1 of the Public Finance Act at the rate of not less than half of their national average, according to data from the last annual report on the implementation of municipal budgets.
The listed conditions also apply to the municipality from which the settlements are separated. In order to initiate the procedure, the request for the establishment of a municipality from one or more settlements should be expressed by a petition of at least 25 percent of the electorate of these settlements to the relevant municipal council. The request shall be accompanied by opinions of the mayors of the settlements on the existence of the 5 legal conditions listed above.

However, the law also provides an exception to the above rules and procedure, namely the Council of Ministers to be able to decide on the establishment of a new municipality under art. 9 of LATSRB, in cases where geographical, economic, communication, historical and other reasons make it impossible to fulfil some of the above conditions. This exception stems from the constitutionally established norm that the Republic of Bulgaria is a unified state with local self-government (Art. 2) and that the municipality is the main administrative-territorial unit in which local self-government takes place and citizens participate in the management of the municipality both through their elected local self-government authorities and directly through a referendum and general assembly of the population (Art. 136).

The LATSRB also determines the conditions for the restoration of deleted localities, which, however, are also not subject to this study.

For all administrative-territorial units at the local level, the law always defines as a first step the participation of the population - with a petition $(25 \%)$ and a subsequent referendum on its closure, respectively a request for the establishment of a mayoralty and a subsequent referendum on its closure. As an explicit requirement in the Law, it is determined that administrative-territorial changes in the administrative-territorial units - districts and municipalities, and in the territorial units settlements and localities are not allowed, in cases where these changes violate the conditions for their establishment. In addition, according to the additional provisions of the LATSRB, a definition of 'closure' is given, namely that it is the consequence of a merger or division of the units and constitutes a basis for their deletion from the Single Classifier.

It is important to note that the Law does not set a special procedure for official changes in the 
administrative-territorial structure of the country, for example, only because of the decrease in the population or due to deterioration of certain conditions. Legally, an objective system for monitoring the conditions for establishing municipalities has not been adopted, as, for example, the Public Finance Act (PFA) (4) defines in detail the terms and conditions for monitoring important fiscal indicators on municipal budgets, for the classification of a municipality as one with financial difficulties, and respectively regulates the procedure for budget work and interaction under these conditions.

Another argument in support of the fact that only one indicator is not sufficient to determine whether or not it is subject to reform (merger, adhesion, division, separation, closure) the separate ATU is the range of the local community, consisting of people and businesses benefiting from the public services provided by the municipality, settlement or locality concerned. It is precisely because of this understanding for a local community, confirmed by the definitions laid down in the PFA that the "local community are citizens and legal persons who have registration, realize activity or use services on the territory of the municipality concerned", the population does not have a significant impact on the need for basic transport and technical infrastructure, but rather the number of properties and types of property. Our country is one of the European countries with the highest share of private homeowners - nearly $99 \%$ of the homes are owned by individuals. Ownership is in most cases related to the use of public services from administrative and technical services to utilities such as electricity supply, water and sanitation, waste collection and disposal, etc. Unfortunately, there is no such indicator in the conditions for the establishment or closure of the ATU that determines the objective need for public services in a particular territory. The relevant ministries decide on the establishment of, for example, a district court, an emergency centre, a police department, a Labour Office Directorate, a Social Assistance Directorate, and other decentralized state structures.

1.3. An experimental study of the indicators for the establishment of a municipality as defined in LATSRB
1.3.1. Condition "population over 6000 people"

It is important to note that in the LATSRB a definition of the indicator used - population number - has not been given. As is known, there are several approaches to determining this indicator: according to data from the Uniform System for Civil Registration and Administrative Services of the Population, maintained by the General Directorate CRAS of the Ministry of Regional Development and Public Works - NSI data for residents with permanent or current address, or NSI data for the last population count and housing. The permanent address is entered in the personal documents, and also the address which serves to compile electoral registers (5). The current address may also allow voting in a designated municipality, but under certain conditions. Both types of address express an individual's will, as opposed to the data that the NSI processes and publishes. According to the methodology used by the NSI, the number and structures of the population at the end of each year are calculated on the basis of the data from the previous year and the data on the natural and physical movement of the population in the current year. (6)

As for the indicator "population of the respective municipality", there are differences in the data from the official sources listed above, and these deviations are presented in Figure 1.

According to data for municipalities with less than 6000 people, residents with a permanent address are registered at 63 municipalities, and those with a current address - at 65 municipalities. In comparison, NSI data show that there are 76 municipalities under 6000 people, and one - Smyadovo with exactly 6000 residents.

The smallest municipality in the country Treklyano, when looking at indicators such as territory or number of settlements - is far from small. According to data on the population of this municipality, the inhabitants with a permanent address are 382 , whereas those with a current address are almost three times higher - 981, as reported by the NSI at the end of 2019 - 815. The municipality is mountainous, near the border, with 19 settlements covering a territory of $237.6 \mathrm{~km}^{2}$. 


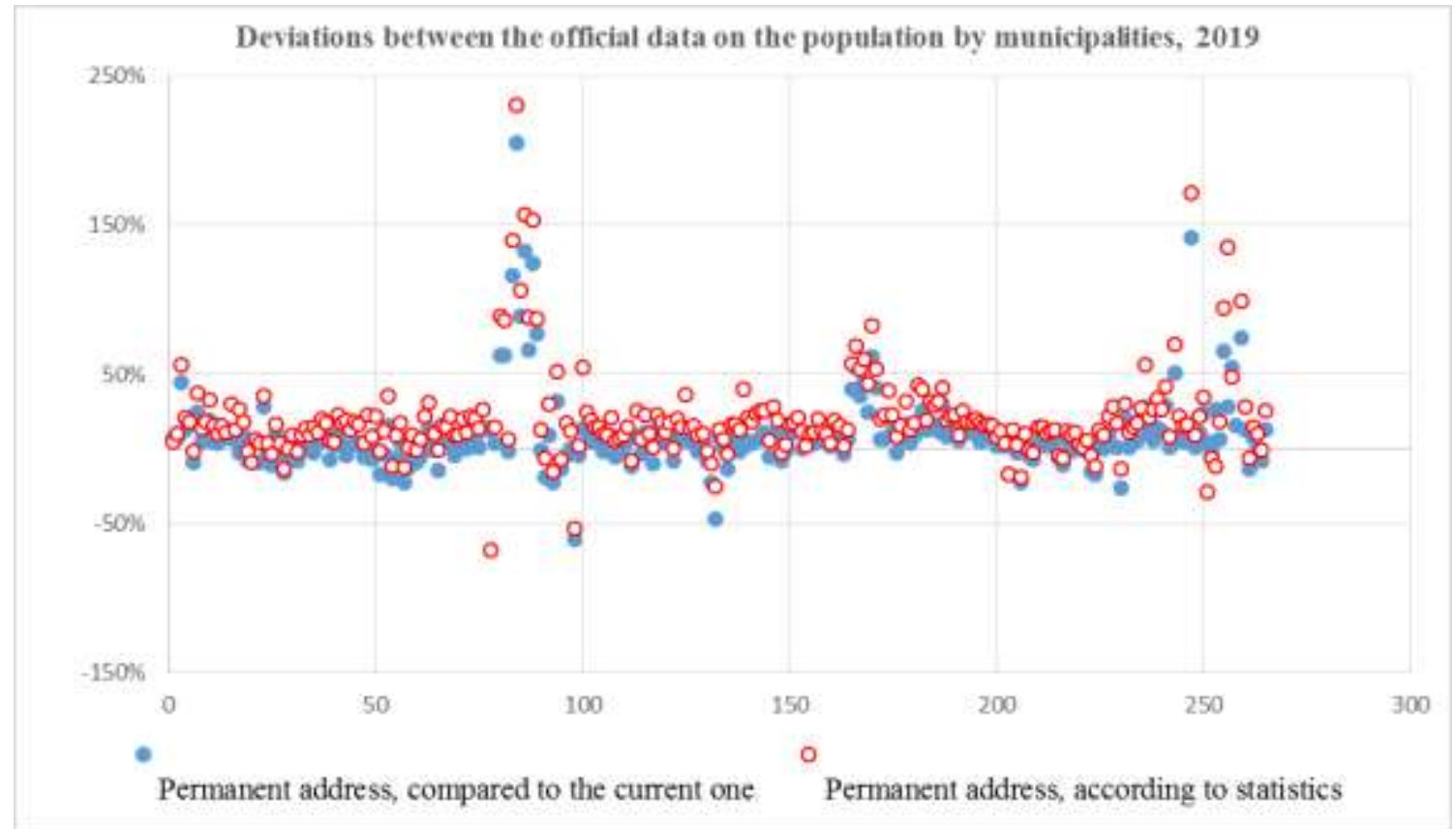

Figure 1. Deviations between the official data on the population by municipalities, 2019 Source: MRDPW, NSI

1.3.2. Presence of "a settlement - a traditional unifying centre with built social and technical infrastructure, providing services for the population"

To assess the existence of a traditional unifying centre with built social and technical infrastructure, providing services to the population, the positions (budget activities) on which the municipalities have reported expenditures have been experimentally studied.
This approach does not explain the existing deconcentrated structures of the state administration, agencies, directorates, departments, etc. Data from the detailed cash reports of the municipalities for 2012 were used, and each activity (according to the uniform budget classification) for which data has been reported is considered a unit.

The results for the municipalities in the country are presented on the next Figure 2.

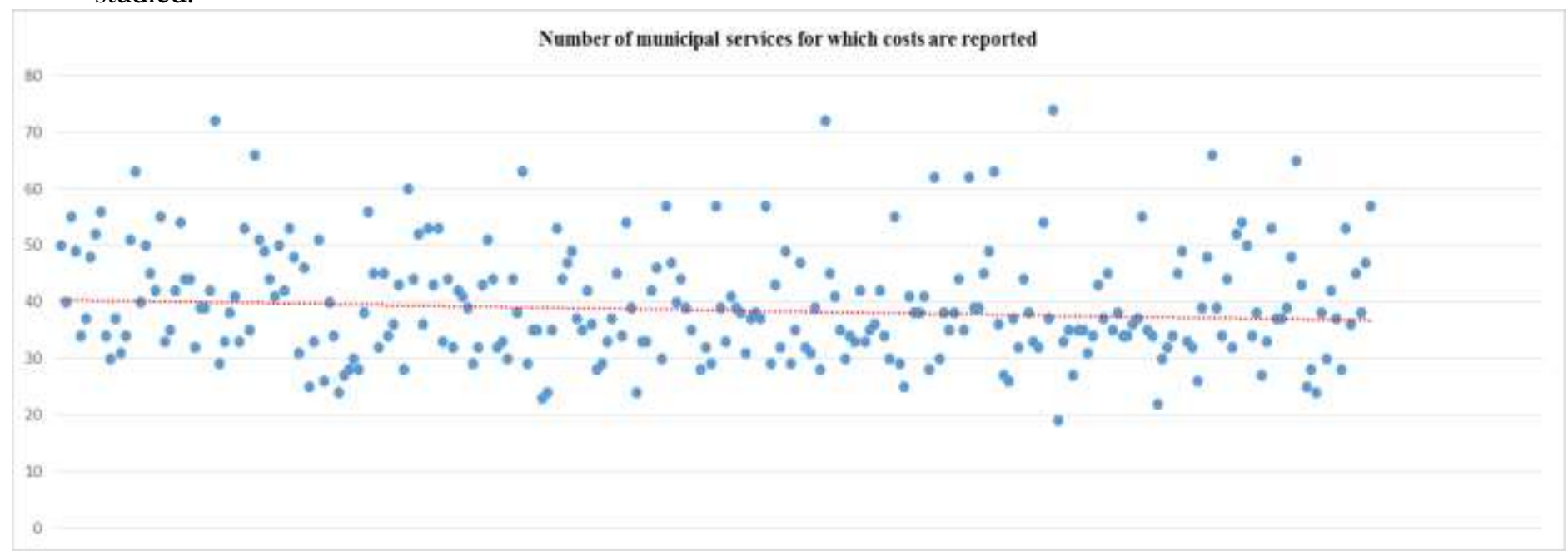

Figure 2. Number of municipal services for which costs are reported Source: NAMRB

It is noteworthy that there is no direct relationship between the population and the number of budget activities for which municipalities report expenditures. In principle, the costs of municipalities depend on the public services provided and the degree of local government to meet the needs of the local population by financing them from the municipal budget. Apart from the administrative and technical services, which 
are initially provided by the municipal administration, there is no municipality without a school, as well as one that does not provide the basic communal services in the local area of responsibility. Such are the maintenance of cleanliness, street lighting, municipal roads and streets, etc.

1.3.3. Condition "inclusion of all neighbouring settlements for which there are no conditions for establishing a separate municipality or which cannot join another neighbouring municipality"
The study of this condition is complicated due to the fact that there is no objective measure for such a type of "redesigning" municipal territory. The inclusion of the neighbouring settlements, in accordance with the principles of local self-government and LATSRB requires the consent of the population in the settlements. In this regard, the average values of the number of inhabitants per settlement in the respective municipalities in the district have been studied. The results for the municipalities in the country are presented on the next Figure 3.

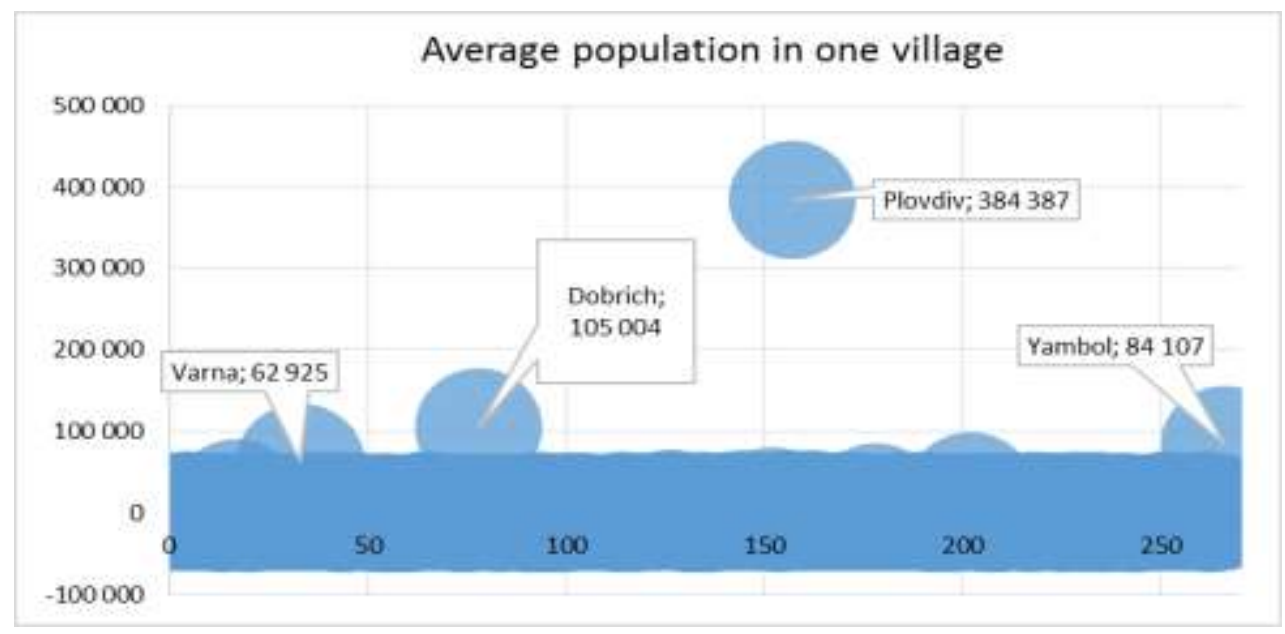

Figure 3. Average population per village

Source: MRDPW, NSI

The data show that there is no direct connection between the number of settlements in the municipalities and their population. The municipalities with the highest number of the population having a permanent address, in practice comprise a different number of settlements - Sofia Municipality has 54 settlements with 1.5 million inhabitants, Plovdiv - only 1 - the city has 384.4 thousand inhabitants, and Varna - only 6 settlements with 377.6 thousand residents. The municipalities with the most settlements according to CRAS, MRDPW are Gabrovo - 134 settlements, Elena - 124 settlements and Kardzhali - 118 settlements. The studied ratio of the population to the number of settlements in the respective municipality proves the same - the municipalities with one settlement such as Plovdiv, Dobrich and Yambol have higher credit values compared to the municipality of Varna, which has 6 settlements. The municipalities of Treklyano (19 settlements), Trun (52 settlements) and Nevestino (23 settlements) have the lowest values of the surveyed indicator - on average about 57 inhabitants per locality.
1.3.4. Condition "maximum road transport distance of the settlements from the centre of the municipality - not more than $40 \mathrm{~km}$ ". 1.3.5.

Due to the energy intensity needed to tackle the transport accessibility from each settlement to the municipal and regional centre, for the purposes of studying this condition we used data for the length of municipal roads versus the number of settlements in the respective municipality. The obtained values were compared to the national average. The results are presented on the next Figure 4.

It is noteworthy that the municipality with the least settlements - Plovdiv has the highest value of indicators - 103.4, followed by the municipality of Anton with 20.7 and Rakitovo with a ratio of 19.9. The lowest indicator for coverage with municipal roads of the settlements in the municipality are the municipalities of Maritsa with 19 settlements and 31.5 thousand residents, Byala, Ruse district - with 11 settlements and 14.4 thousand inhabitants and Velingrad - with 21 settlements and 29.1 thousand inhabitants. 


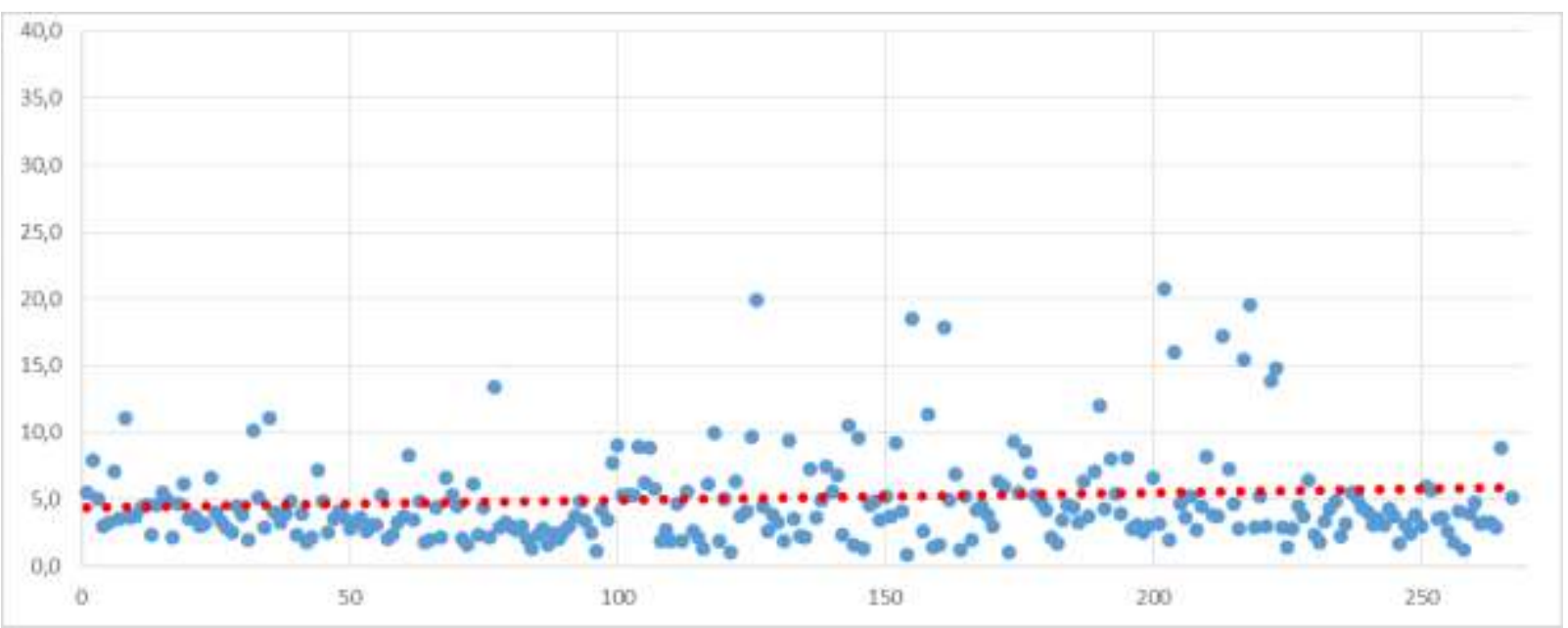

Figure 4. Average number of kilometres of municipal roads per village Source: MRDPW

1.3.6. Condition "possibility for compensating the expenses with revenues within the meaning of art. 45, para. 1, item 1 of the PFA in the amount of no less than half of their average level for the country", according to data for 2019.

The possibility of financing the expenditures with own revenues largely depends on the capacity of the municipality to generate such revenues. On the one hand, legislation, particularly the Local Taxes and Fees Act determines the revenue sources of municipalities. On the other hand, it is up to local governments, in accordance with the solvency of local people and businesses to determine optimal and socially affordable rates of local taxes and fees improve revenue collection and responsibly manage the municipal budget. To assess the fulfilment of this condition, the data on the financial indicators of the municipalities, published quarterly on the website of the Ministry of Finance (7), have been used.

The results, according to the data reported by the municipalities at the end of 2019 are presented in the following Figure 5.

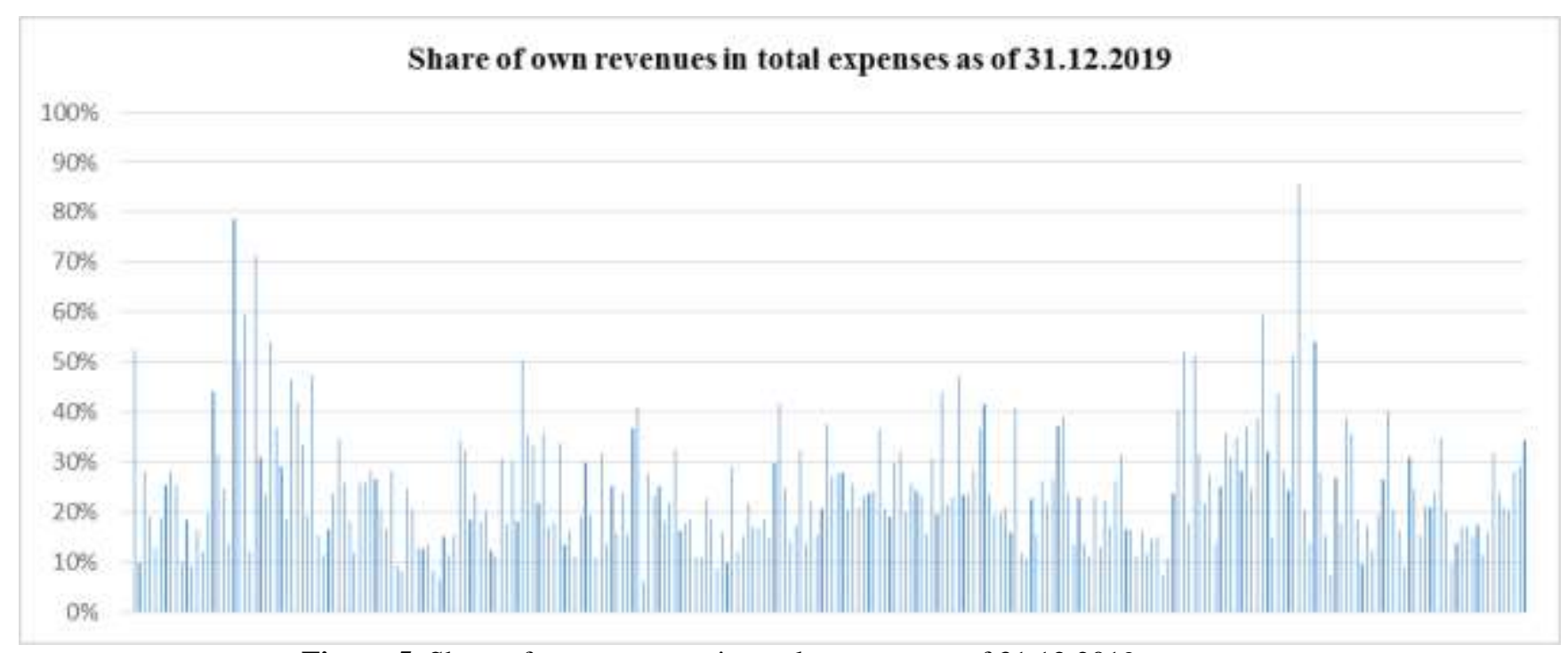

Figure 5. Share of own revenues in total expenses as of 31.12.2019 Source: MF

The municipalities of Chelopech (1,485 inhabitants), Nessebar $(26,408)$ and Sozopol $(13,462)$ have the highest (over $70 \%$ ) share of own revenues in expenditures. The municipalities with the lowest values (less than
$7 \%)$ are Nedelino $(6,985)$, Ruzhintsi $(3,812)$ and Treklyano (382).

\section{CONCLUSION}

Local self-government is defined as a basic constitutional norm of state organization and 
administration. The model of the administrative-territorial structure should ensure the efficiency of the functioning of the separate administrative-territorial structures. Under crisis conditions, it can be said that the systems of the administrative division of the country are tested, respectively the work of the separate administrative-territorial units and the bodies that manage them. In such situations, the flexibility of the executive bodies to implement relevant policies at the level of the region, district, municipality, settlement, to implement local government and to ensure consistency between national and local interests can be assessed. The level of decentralization in governance, and in particular financial decentralization, is largely decisive in tackling this task.

In this sense, the derivation of a single indicator for future administrative reforms, such as the number of population in the municipality, is unjustified and poses a number of risks to the access of local communities to basic services. The experimental study of the conditions for establishing a municipality, using up-to-date information on the municipalities in the country, confirms this conclusion, as there is no municipality that does not meet both the five conditions defined in the LATSRB. On the other hand, in the current situation caused by the coronavirus crisis, the municipalities effectively and responsibly are meeting the challenge and fulfilling their legally defined commitments to the local population.

\section{REFERENCES}

1. Nedkov, R. P., System analysis of the horizontal network of administrativeterritorial units in Bulgaria, p. 12, Sofia University

2. Draft of the Updated National Concept for Spatial Development for the period 20132025, December 2019

3. Law on the Administrative-Territorial Structure of the Republic of Bulgaria, https://www.lex.bg/laws/ldoc/2133622784

4. Public Finance Act, https://www.lex.bg/laws/ldoc/2135837967

5. Electoral Code, https://www.lex.bg/laws/ldoc/2136112596

6. https://www.nsi.bg/bg/content / 2975 /\% D0\% BD\% D0\% B0\% D1\% $81 \%$ D0\% $\mathrm{B} 5 \% \quad \mathrm{D} 0 \% \quad \mathrm{BB} \% \quad \mathrm{D} 0 \% \quad \mathrm{~B} 5 \% \quad \mathrm{D} 0 \% \quad \mathrm{BD} \%$ $\mathrm{D} 0 \% \quad \mathrm{~B} 8 \%$ D0\% $\mathrm{B} 5-\% \quad \mathrm{D} 0 \% \quad \mathrm{BF} \%$ D0\% $\mathrm{BE}-\%$ D0\% BE\% D0\% B1\% D0\% BB\% D0\% B0\% D1\% 81\% D1\% 82\% D0\% B8$\%$ D0\% BE\% D0\% B1\% D1\% 89\% D0\% B8\% D0\% BD\% D0 \% B8-\% D0\% BC\% $\begin{array}{lllllll}\mathrm{D} 0 \% & \mathrm{~B} 5 \% & \mathrm{D} 1 \% & 81 \% & \mathrm{D} 1 \% & 82 \% & \mathrm{D} 0 \%\end{array}$ $\mathrm{BE} \% \mathrm{D} 0 \% \quad \mathrm{~B} 6 \%$ D0\% $\mathrm{B} 8 \%$ D0\% $\mathrm{B} 2 \%$ D0\% B5\% D0\% B5\% D0\% BD\% D0\% B5$\%$ D0\% B8-\% D0\% BF\% D0\% BE\% D0\% $\mathrm{BB}$

7. Financial data for municipalities under Art. $130 \mathrm{~g}$, para. 2 of the PFA by the end of 2018 and towards the end of 2019, as well as data in relation to Art. 130c, para. 1 of the PFA, https://www.minfin.bg/bg/810 